\title{
An update on chemical eye burns
}

\author{
Mukhtar Bizrah ${ }^{1} \cdot$ Ammar Yusuf $^{2} \cdot$ Sajjad Ahmad ${ }^{3}$
}

Received: 8 January 2018 / Revised: 6 February 2019 / Accepted: 2 April 2019 / Published online: 13 May 2019

(c) The Royal College of Ophthalmologists 2019

\begin{abstract}
Ocular chemical injuries vary in severity, with the more severe end of the spectrum having profound visual consequences and medicolegal implications. Grading of ocular injuries is critical for determining acute treatment and visual prognosis. Poor immediate management results in more challenging treatment of acute disease. Similarly, poorly controlled acute disease results in more treatment-resistant chronic ocular disease. Despite several decades of research and public health initiatives, simple and effective interventions such as wearing protective eyewear and immediate irrigation of eyes remain as key challenges. Education and prevention are therefore important public health messages. Hurdles in the acute management of disease include poor evidence-base for commonly used treatments (e.g. based on experimental animal studies), reduced treatment adherence rates and high clinic non-attendance rates. The evolution of treatment strategies, particularly limbal stem cell transplantation, has revolutionised the visual and cosmetic outcomes in chronic phases of disease. It is therefore increasingly important to consider tertiary referral for patients with limbal stem cell failure or vision-limiting corneal scarring.
\end{abstract}

\section{Introduction}

Severe ocular chemical burns are an ophthalmic emergency requiring immediate treatment. Chemical eye injuries can have a devastating impact on patient's vision and quality of life. Effective management starts from developing effective prevention strategies and first-aid measures. Following an ocular burn, the disease process has several stages that require specialist ophthalmologyled treatment focusing on each stage of disease process [1]. Timely and adequate management of each stage of the disease results in improved visual outcome and reduced complication rates.

The prognosis for a severe ocular chemical burn has classically been poor. However, evolution in therapeutic strategies has significantly improved visual outcomes. This is an up to

Mukhtar Bizrah

mbizrah@gmail.com

1 Imperial College Healthcare NHS Trust, Western Eye Hospital, 153-173 Marylebone Road, London NW1 5QH, UK

2 UCL Institute of Ophthalmology, 11-43 Bath Street, London EC1V 9EL, UK

3 Moorfields Eye Hospital NHS Foundation Trust, 162 City Road, London EC1V 2PD, UK date review of the epidemiology, aetiology, classification and management of ocular chemical burns.

\section{Epidemiology}

\section{Adults}

Chemical burns are amongst the most common workplace related injuries [2,3]. In a study of 101 patients in Germany, a total of 131 severe ocular burns were recorded, of which $84 \%$ were chemical injuries, mostly alkali chemicals (80\%) and $72 \%$ were work-related [4]. Similar trends in terms of the epidemiology of these chemical eye injuries has been reported in the literature [4-10]. About two-thirds occur at work, in people of working-age group and with alkali chemicals. Furthermore, men are more commonly affected than women (ratio 3-8:1). The proportion of chemical injuries due to alkali is particularly worrying, as highly alkali agents are known to result in the most severe ocular burns. For example, a study of severe ocular chemical injuries in China reported that $70 \%$ of inpatients with severe ocular chemical burns had an alkali injury [9]. Once again, most of the injuries $(75 \%)$ occurred in the workplace, with factory and construction workers being the most common. This makes sense as alkali agents are known to be more 
commonly used in construction and cleaning/sanitising agents (see Table 1). The majority of work-related eye injuries occur in those not wearing protective eyewear at the time, and such protective eyewear reduces the odds of eye injury [9, 11].

More recently, two of the largest epidemiological studies of chemical eye injuries have been carried out in the United States (US). These studies have shed more light on the incidence and financial burden of such injuries. In an observational retrospective study of 961 emergency departments in the United States, a mean of 15,865 new chemical burn cases per year were identified, resulting in an incidence rate of 51.10 new cases per million per year [12]. This correlates well with a recently published prospective study in the United Kingdom (UK). Based on 11,683 patients attending an emergency department over 6 months, the incidence was estimated to be 56 new cases per million [13]. This incidence rate may therefore closely reflect that of other developed countries. It is more challenging to extrapolate such data to developing countries, which may show substantial variation in incidence.

In another large study of 900 nationwide emergency departments in the US, 144,149 chemical ocular burns were diagnosed [7]. In total, $56.6 \%$ of cases occurred in men, median age was 32 years, and $56 \%$ occurred in individuals in the two lowest income quartiles. In total, $53.6 \%$ of injuries were due to alkali, but the chemical agent was known in only $11.8 \%$ of cases. It is also important to note that chemical conjunctivitis was included in the diagnostic criteria, which represents a mild form of chemical eye injury rather than a chemical 'burn'. The study also included all age groups, including infants and children. These factors would explain why alkali agents and work-related injuries accounted for less proportion of injuries than aforementioned studies of severe ocular burns. Nevertheless, it is important to report causes of mild injuries, as well as incidence and causal factors in children, which are often neglected in literature on ocular chemical burns. This study calculated the cost of emergency departments' charges only (which does not include further outpatient and interventional therapies) over 1 year to be $\$ 26.6$ million. As far as we know, the financial impact of chemical eye injuries in the United Kingdom has not been thoroughly investigated. However, if one is to infer this data to the population of the UK (fifth of US population), then annual emergency department costs alone would be in the region of $\$ 5.3(£ 4.2)$ million.

Over the years, an upward trend in chemical eye injuries due to assault has been reported. In the United Kingdom (UK), an alarming increase in assault-related chemical burns was reported as early as 1980s $[10,14,15]$. Over the last few years, an increase in chemical-burn assaults has also been suggested [16]. In terms of eye injuries, the British Ophthalmological Surveillance Unit found that assault accounted for $33.3 \%$ of severe chemical ocular injuries occurring between Dec 2005 and Nov 2006 [11]. This is of concern, as chemical injuries caused by assault are known to cause more severe and permanent injury to eyes [8, 17]. This may be due to the highly toxic nature of the chemicals causing the injury (e.g. ammonia), or the fact that first-aid kit (e.g. irrigating solutions) and guidelines to immediate treatment are less readily available on the roadside than in workplaces. A study looking at patients presenting to Moorfields Eye Hospital emergency department in London from Jan 2016 to March 2016 identified 84 patients with chemical eye injuries [18]. Eleven patients had severe injuries, and 55 patients had mild chemical burns. Seventy percent of severe chemical eye injuries were assault-related, correlating with the aforementioned BOSU finding. Astonishingly, $30 \%$ of patients with severe chemical burns presented to an emergency department more than 24 hours after the injury, and $36 \%$ did not comply with treatment. Patients with mild chemical injuries maintained their preinjury level of vision, but $36 \%$ of severe chemical burns resulted in a final BCVA of $6 / 18$ or worse.

\section{Children}

A recent epidemiological study found that between January 2010 and December 2013, a total of 144,149 chemical ocular burns were diagnosed at emergency departments across the United States [7]. Of note in this study, the agespecific risk for chemical ocular injuries is highest among 1and 2-year-old children. This serves to highlight the importance of potentially dangerous chemicals and the importance of safe keeping, education and prevention. A review of the literature reported that most chemical injuries in children are accidental [19]. Chemical agents included household cleaning agents, industrial chemicals, medications, and agricultural chemicals. Biological agents reported were millipedes, snake venom, vesicatory insects, and Manchineel tree sap. A large epidemiological study in the US identified household cleaning agents to be the most common chemicals causing eye injuries in children [7]. Generalised body burns in children under the age of 10 years in the developed world are also most frequently due to household cleaning agents [20]. Laundry detergent pods are a particularly frequent cause of chemical eye injury in children [21]. An important finding was that most of these injuries are preventable, emphasising the importance of public health measures and education in prevention of such injuries. Interestingly, a small UK case series looking at paediatric liquid detergent capsule eye injuries found that resultant corneal burns resolved without sequelae in all children (mean time to epithelial closure $=2.5$ days) [22]. 
In the developing world, delay in presentation is a major challenge. In a recent study of 134 paediatric patients with chemical eye burns in India, the average time between injury and presentation was found to be 68.3 days [23]. This is a worrying lag to management, especially considering that $70.1 \%$ had a grade III-IV (Roper-Hall classification) chemical injury, and $85 \%$ required surgical intervention. The median best-corrected visual acuity at final follow-up was 3/60. This data illustrates additional challenges in the developing world which are rarely encountered in the developed word. Such a delay in presentation means there was little or no treatment in the acute and early reparative phases. This is particularly worrying considering the reported severity of chemical burns, and may therefore explain the high proportion of patients requiring surgical intervention and ending up with poor final visual acuity.

This epidemiological data sheds light on the substantial global burden of ocular chemical injuries in children and adults, and the need for public health and education measures to the community at large. For children in particular, use of child-resistant packaging, locked or out of reach cabinets and parental/guardian education are important primary prevention strategies [20].

\section{Alkali vs acid chemical agents}

Alkali is a more common cause of severe ocular chemical burns than acid, with lime plaster being the most common $[10,24,25]$. The fraction of severe ocular chemical burns caused by alkali vary in the literature, with approximately two-thirds being a commonly reported proportion $[9,11]$. A key factor determining toxicity of the alkali is the $\mathrm{pH}$ [26], with a $\mathrm{pH}>11.5$ resulting in significant corneal damage [27]. Alkali chemicals have a higher penetration rate than acids, and this has been long recognized [25]. Of the common alkali substances which cause severe ocular burns, ammonia has the fastest penetration rate $(<3 \mathrm{~min})$. This is followed by sodium hydroxide (3-5 $\mathrm{min})$, potassium hydroxide (>5 min) and calcium hydroxide (slowest and variable depending upon crystallisation) [28]. Therefore, ammonia is known to cause most severe ocular chemical burns [13] and is used commonly in assault cases. Lime is a much more common cause of chemical burns, but comparatively less toxic. It produces calcium soaps after penetration of the corneal epithelium, hindering further penetration. Acid injuries cause more limited damage of the ocular surface than alkali. Concentrated acid results in denaturation and coagulation of the corneal epithelium and anterior stroma protein, hence resulting in opacification. This coagulated protein limits deep penetration of the acid into the corneal stroma [27]. Furthermore, the buffering properties of the corneal epithelium and anterior stroma enables neutralisation of the low $\mathrm{pH}$ [29]. The most common cause of acid ocular injury is sulfuric acid, which is much less likely to result in severe ocular injury (unless associated with thermal or highvelocity injury, e.g. battery explosion). Unlike other acids, however, hydrofluoric (HF) acid has a powerful dissolving action on cell membranes and has a similar ability to alkali to penetrate into the anterior chamber [30]. HF acid can result in severe cornea stromal scarring and vascularisation, as well anterior segment injury as described previously with alkaline injuries (e.g. uveal inflammation, ciliary body fibrosis).

\section{Grading the chemical eye injury}

For the purposes of both treatment and prognosis, it is important to have a classification system for chemical eye burns. Severe chemical burns are not seen often, and a classification system would therefore serve as an aid to the ophthalmologist to guide examination, documentation of findings and tailoring treatment. It also serves as a reminder to the ophthalmologist examining about the importance of meticulous documentation, as these cases often have medicolegal implications.

A number of classification systems have been developed and are in clinical use. The two most commonly used systems in clinical practice are the Roper-Hall classification and the Dua et al. classification.

The Roper-Hall classification [31] is a modification of a classification system developed by Ballen et al. [32] (Table 1). This system is based on the extent of cornea injury and limbal conjunctival ischaemia. The latter has long been recognised as a key marker of limbal stem cell damage [26], which has major implications for short- and long-term ocular surface recovery.
Table 1 Roper-Hall classification of severity of ocular surface chemical burns (adaptation) [31]

\begin{tabular}{llll}
\hline Grade & Prognosis & Cornea & Limbus \\
\hline I & Good & Corneal epithelial damage & No limbal ischaemia \\
II & Good & Cornea haze, iris details visible & $<1 / 3$ limbal ischaemia \\
III & Guarded & Total epithelial loss, stromal haze, iris details obscured & $1 / 3-1 / 2$ limbal ischaemia \\
IV & Poor & Cornea opaque, iris \& pupil obscured & $>1 / 2$ limbal ischaemia \\
\hline
\end{tabular}


Table 2 Dua et al. classification of ocular surface chemical burns

\begin{tabular}{lllll}
\hline Grade & Prognosis & Clinical findings & Conjunctival involvement & Analogue scale \\
\hline I & Very good & 0 clock hours of limbal involvement & $0 \%$ & $0 / 0 \%$ \\
II & Good & $\leqslant 3$ clock hours of limbal involvement & $\leqslant 30 \%$ & $0.1-3 / 1-29.9 \%$ \\
III & Good & $>3-6$ clock hours of limbal involvement & $>30-50 \%$ & $3.1-6 / 31-50 \%$ \\
IV & Good to guarded & $>6-9$ clock hours of limbal involvement & $>50-75 \%$ & $6.1-9 / 51-75 \%$ \\
V & Guarded to poor & $>9-<12$ clock hours of limbal involvement & $>75-<100 \%$ & $9.1-11.9 / 75.1-99.9 \%$ \\
VI & Very poor & Total limbus (12 clock hours) involved & Total conjunctiva (100\%) involved & $12 / 100 \%$ \\
\hline
\end{tabular}

The Roper-Hall classification is an important classification system of accurate prognostic value, is in wide clinical use, and is simple to follow. It has been utilised in various clinical trials $[33,34]$. A weakness of this classification system is that it does not factor in conjunctival injury. This has been shown clinically to be of value in predicting prognosis for corneal melting and symblepharon formation [35]. Another recognised weakness of this classification method is that it classifies all injuries with $>50 \%$ limbal ischaemia as a grade IV (i.e. same level of severity). For example, an eye with 7 clock hours of limbal ischaemia receives the same grading as an eye with 12 clock hours of limbal ischaemia. However, the evolution of treatments such as limbal stem cell transplantation has significantly improved prognosis for severe chemical ocular injuries. These treatment modalities were not well established during the development of Roper-Hall classification.

The Dua et al. classification system [36] (Table 2) has been developed to enable more accurate stratification of prognosis, particularly for severe injuries. It was originally based on experience with 67 chemical-burn cases (35 retrospective, 32 prospective). The method factors in conjunctival injury (percentage) and limbal injury (clock hours). A key difference between the Roper-Hall classification and Dua et al. classification is the method of assessment of limbal stem cell injury (Fig. 1). Whilst the former relies on the presence of perilimbal ischaemia, the latter requires the presence of fluorescein staining of the limbal area. The rationale given by Dua et al. is that even in the presence of minor limbal ischaemia, complete loss of limbal epithelium can indicate extensive stem cells loss. Of note, Dua et al. classification does not take into account corneal involvement.

Once the extent of conjunctival and limbal injuries have been quantified, an analogue score can be calculated. This facilitates monitoring of the healing process. Even if the grade of chemical burn remains unchanged, the analogue scale can assist in detecting improvement or worsening.

Potential drawbacks of the Dua et al. classification scheme is that some clinicians find the analogue scheme difficult to use, and that it does not take into account corneal involvement or limbal vascularity.

\section{Roper-Hall or Dua et al.?}

The most commonly used classification systems in clinical practice are Roper-Hall and Dua et al. methods. To date, the most robust study comparing these classification systems is a prospective trial by Gupta et al. [37]. In this study, 100 patients were studied prospectively and followed up for $13.2 \pm 3.8$ months. Of these patients, 50 were graded as moderate (Roper-Hall and Dua et al. grade II) and 50 as severe (Roper-Hall grade IV and Dua et al. grade IV, V \& VI) ocular burns. Patients were randomised to receive AMT combined with medical therapy or conventional medical therapy alone.

In patients treated with medical therapy alone, there was a statistically significant difference in the extent of corneal vascularisation in grade IV and grade VI ocular burns by Dua et al. classification. There was no statistically significant difference in time to healing of the epithelial defect. In the group of patients treated with standard medical therapy and AMT, grade IV burns had significantly better corneal clarity, final visual acuity and less corneal vascularisation as compared with grade VI. AMT significantly reduced symblepharon formation in group IV but not in group VI.

Interestingly, patients with up to $25 \%$ conjunctival involvement had significantly less corneal vascularisation than those with $100 \%$ conjunctival epithelial loss. Symblepharon formation showed correlation with degree of conjunctival epithelial loss. This therefore highlights the relevance of grading of conjunctival de-epithelialisation in chemical ocular injuries.

In another important retrospective study of acute ocular chemical burns (over a 10 year period) presenting to two centres in Europe, all patients were graded by both Roper-Hall and Dua et al. methods [38]. Average patient follow-up was 36.4 months. Limited additional prognostic benefit was reported by the authors for using the Dua et al. classification over Roper-Hall. Patients graded as IV by Dua et al. had possibility of improvement to partial LSCD and improvement in VA. Grades V and VI had very poor prognosis. 


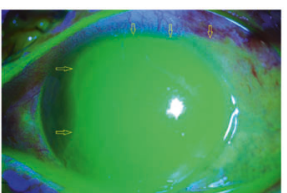

Eye 1: Limbal staining from 1 to 8 o'clock, and large but non-total cornea and conjunctival epithelial defect (yellow arrows) of left eye. No limbal ischaemia seen superonasally. Good visual prognosis expected as corneal epithelium heals from superonasal limbal area.

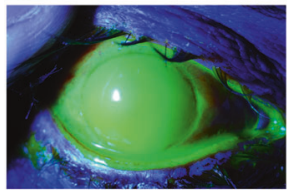

Eye 2: Total epithelial defect involving entire right cornea, limbus and bulbar conjunctiva. Dua et al Grade VI classification, indicating poor visual prognosis.

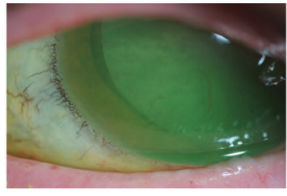

Eye 3 (image1): Assault-related ammonia ocular burn. Severe limbal ischaemia which extends 360 degrees (Roper-Hall Grade IV), hazy cornea, cataract formation, sclerosed limbal and

conjunctival/scleral vessels, implying anterior segment ischaemia and very poor prognosis.

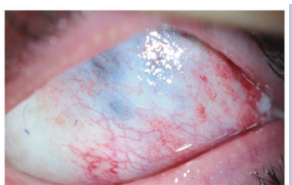

Eye 3 (image 2): Same eye undergoes buccal mucous membrane graft for prevention of corneo-scleral melt. Severity of anterior segment ischaemia puts this graft at risk of ischaemic necrosis.

Fig. 1 Different stages of ocular surface burns

The above studies suggest that the benefit of the Dua et al. classification is that it helps identify patients who are grade IV rather than grade V or VI. Grade IV patients have a better prognosis in terms of visual acuity and risk of complications. There is no compelling evidence of a difference in prognosis between grade $\mathrm{V}$ and VI chemical burns.

Is it not clear whether the advantage of Dua et al. is due to sub-classification into clock hours, or the use fluorescein staining as marker of limbal stem cell injury as opposed to presence of limbal ischaemia. Arguably, calculating extent of limbal ischaemia in clock hours (e.g. 7 clock hours instead of simply $>6$ clock hours) may yield similar prognostic benefits for patients with severe injury. Accurate clinical grading of extent of limbal ischaemia is, however, limited by poor interrater consistency, even amongst corneal specialists [39]. Anterior segment angiography may therefore play a vital role in more accurate assessment of limbal vascularity.

One could infer from these findings the importance of grading exact number of clock hours of limbal staining and/ or ischaemia. This may allow better stratification of injury severity, and more tailored treatment regimens.

\section{Further considerations}

A major flaw in current classification systems is that although the surface area of injury is well graded, they do not consider depth of injury. In the current clinical setting, more commonly available imaging modalities such as anterior segment OCT may help in documenting depth of involvement to some degree $[40,41]$.
However, these imaging modalities are not always available, and their role has not been thoroughly studied in ocular chemical injuries. It is not possible therefore to make recommendations about their role in assessment of chemical-burn severity or progress. In addition to grading of injury, photographic imaging and documentation of intraocular pressure and the preseniris or lens involveme/iris or lens involvement (Fig. 1) as important indicators of depth of injury are also important.

\section{Management}

The management of chemical eye injuries can be divided based on the four phases of healing: immediate, acute, early reparative and late reparative (Table 3 ).

\section{Immediate management-Irrigation therapy}

Following decades of research into treatment strategies, the most important intervention in chemical injuries treatment remains to be timely irrigation of the eye. This effectively reduces severity of chemical burns, reduces need for surgical intervention and improves final visual acuity [4]. This should be done before any comprehensive examination of the eye is performed to avoid delay. This is based on the well-recognized highly penetrating rate of severe alkali chemicals such as ammonia, which can take seconds to penetrate into the anterior chamber [42]. Animal studies have highlighted the importance of immediate irrigation in preventing $\mathrm{pH}$ changes of the aqueous [43]. 
Table 3 Phases of injury following a chemical burn [1]

\begin{tabular}{|c|c|c|}
\hline Phase & Time (days) & Findings \\
\hline Immediate & 0 & $\begin{array}{l}\text { Mild chemical burns result in limited conjunctival and corneal epithelial defects. More severe injuries result in } \\
\text { more extensive epithelial defects affecting the limbus, limbal ischaemia, corneal haze, raised intraocular pressure } \\
\text { and intraocular damage (e.g. lens opacification). }\end{array}$ \\
\hline Acute & $0-7$ & $\begin{array}{l}\text { Inflammation plays a critical role here, and can contribute to ocular surface melting. Rate and success of re- } \\
\text { epithelialisation is multifactorial, being influenced by health of limbal stem cells, presence of growth factors, } \\
\text { ocular surface dryness, etc. Rapid changes in corneal transparency occurs in the days following injury. } \\
\text { Intraocular pressure can be affected at all stages of injury, and must be frequently monitored. }\end{array}$ \\
\hline Early reparative & $7-21$ & $\begin{array}{l}\text { This is the transition period where regeneration of the ocular surface and the acute inflammatory response gives } \\
\text { way to scarring, stromal repair and chronic inflammation. Milder injuries complete re-epithelialisation and more } \\
\text { severe injuries can develop persistent epithelial defects. }\end{array}$ \\
\hline Late reparative & $>21$ & $\begin{array}{l}\text { Mild chemical-burns display adequate healing and subsiding of inflammation. Localised limbal stem cell } \\
\text { deficiency (LSCD) can result in sectorial conjunctivalisation (pseudopterygium) of the cornea. In more severe } \\
\text { injuries, persistent epithelial defects can result in permanent scarring and secondary infections. Limbal stem cell } \\
\text { deficiency and development of conjunctival cicatrisation, lid abnormalities and dry ocular surface result in } \\
\text { conjunctivalisation and vascularisation of the cornea. Glaucoma is an often missed cause of irreversible } \\
\text { visual loss. }\end{array}$ \\
\hline
\end{tabular}

Irrigation of the eye should ideally be performed with isotonic saline or lactate ringer solution, and continued until the $\mathrm{pH}$ neutralises to a physiological level. If this is not readily available, water can be used as an alternative. Topical anaesthesia should be used, as irrigating an inflamed ocular surface with denuded epithelium is very painful. A speculum can be used to aid irrigation if available, and we recommend ocular irrigation with at least 11 of fluid and for at least $30 \mathrm{~min}$. It is also important that any solid debris is removed from fornices and subtarsal tissues (under the upper lid) to prevent persistent accumulation of toxic chemicals. For example, lime (most common cause of alkaline chemical injuries) can form precipitates. It can rapidly react with water to produce a calcium hydroxide solution $(\mathrm{pH}=12.4)$ [44]. Care must therefore be taken to remove debris from the fornices. If these crystals are not removed, the alkaline chemical will re-accumulate after irrigation. It is therefore recommended to sweep the fornices and to double evert the lid to remove any persistent residues. It is also recommended to check the $\mathrm{pH}$ regularly at regular intervals post irrigation for up to 1 hour in all cases of chemical ocular injuries.

\section{Irrigation techniques}

In a non-healthcare facility, a standard IV set may not be available for ocular irrigation. The most critical factor in this scenario is timely delivery of irrigating fluid. Therefore, any method of rinsing the eye safely (e.g. under tap water with the eyes open) is preferable than delay in elimination of the toxic chemical. Using a standard IV set enables rapid delivery of copious irrigation. For decades, it has been the gold-standard method of ocular irrigation. It remains the most readily available and commonly used method in the healthcare setting.
The Morgan lens is specially-designed delivery system which enable continuous irrigation of the ocular surface, as well as delivery of medications. It also enables flushing out of non-adherent debris. It is composed of a moulded lens with directional fins, attached tubing and a standard luer loc adapter. The Morgan Delivery Set or a standard IV set can be used to attach it to a standard bag of irrigating solution (e.g. normal saline).

Topical anaesthetic drops aide the healthcare provider in providing more copious irrigation by reducing ocular discomfort. Arguably, however, it may increase penetration of the offending chemical into the anterior chamber. This may be especially true for rapidly penetrating chemicals such as ammonia. It may therefore be preferable to minimise use of anaesthetic eye drops, particularly the more potent types (e.g. tetracaine). Furthermore, to minimise penetration of the offending chemical, one could initially irrigate the eye without anaesthetic, and thereafter use topical anaesthetic to provide more copious irrigation. The authors, however, emphasise the importance of providing immediate sufficient irrigation, even if use of topical anaesthetic is the only means by which this achievable.

\section{Irrigation solutions}

It is important to further emphasise that immediate irrigation of the eye should not be delayed by choice of irrigating solution. This is especially in light of the fact that there are no robust trials comparing irrigating fluids, and evidence for beneficial effect of one irrigating fluid over others is not yet substantiated [45]. Studies have shown that immediate irrigation with tap water is of benefit in minimising the severity of chemical burns, reducing penetration of alkali into the aqueous and improving healing time [43, 46, 47]. 
It is important to note that most studies about choice of irrigating fluid are either in vivo studies or small nonrandomised studies, many which are observational.

As water is hypotonic in comparison to the cornea stroma, there are some concerns regarding the osmosis of water enabling the offending chemical to enter deeper layers of the corneal stroma [48]. In a study on chemically burnt porcine eyes, corneal thickness and osmolarity were significantly correlated to osmolarity of the rinsing solution [49]. In an ideal setting, immediate irrigation with a buffering solution is preferable to water or other isotonic solutions. This is because buffering solutions have a good binding capacity to bases and acids, and have less exothermic reactivity. They have been shown to have an enhanced ability in reducing aqueous humour $\mathrm{pH}$ following alkali ocular burns in ex vivo rabbit models [43, 50]. In a prospective comparative non-randomised observational case series in humans, Diphoterine ${ }^{\circledast}$ was compared with normal saline as irrigation fluid for ocular chemical injuries [51]. No significant difference in vision or corneal opacification were observed between the two treatment groups. In Roper-Hall grade I-II injuries, Diphoterine ${ }^{\circledR}$ was shown to significantly reduce time to corneal re-epithelisation. More clinical trials in humans showing beneficial effect on vision or reduction in long-term complications are needed before it can be recommended as a gold-standard irrigating fluid. Lack of availability for immediate use is another major obstacle to its widespread use.

Once eye irrigation is completed and $\mathrm{pH}$ is neutralised, a comprehensive examination can be performed. Severe pain and inflammation is expected, and so topical anaesthesia is used to facilitate ophthalmic examination. In young children, examination under general anaesthesia may be needed.

\section{Acute management of mild chemical burns}

The definition of a mild injury would include the absence of any limbal involvement or stromal loss. In such cases, topical steroids promote healing by reducing inflammation and protease production, and ocular lubricants provide a positive environment for epithelial healing. In the presence of epithelial defects, topical antibiotics act as prophylaxis against infection. Here the goals are to normalise the corneal epithelium as rapidly as possible and prevent stromal loss or infection.

\section{Acute and early reparative management of severe chemical burns}

The main principles of acute management of severe ocular chemical burns are anti-inflammatory therapy, halting epithelial and stromal breakdown, promoting re-epithelialisation and promoting corneal stromal healing (see Table 4).

\section{Anti-inflammatory therapies}

Severe chemical injuries results in tissue necrosis and resultant profound inflammation, which can lead to a

Table 4 Acute medical treatment of severe ocular chemical burns

\begin{tabular}{|c|c|c|}
\hline Medical Treatment & Key aims ${ }^{\mathrm{a}}$ & Suggested choices or dose \\
\hline $\begin{array}{l}\text { Broad-spectrum topical } \\
\text { antibiotics }\end{array}$ & $\begin{array}{l}\text { Prophylaxis against infection in presence of epithelial } \\
\text { defects. }\end{array}$ & $\begin{array}{l}\text { Topical PF fluoroquinolones or chloramphenicol four } \\
\text { times a day }\end{array}$ \\
\hline Potent steroid eye drops & $\begin{array}{l}\text { Reduce inflammation and proteolytic enzyme } \\
\text { release, preventing uveitis and stromal melting. }\end{array}$ & $\begin{array}{l}\text { Topical PF dexamethasone } 0.1 \% \text { or prednisolone acetate } \\
1 \%, 1-2 \text { hourly }\end{array}$ \\
\hline $\begin{array}{l}\text { Potassium ascorbate } 10 \% \\
\text { eye drops }\end{array}$ & $\begin{array}{l}\text { Co-factor for collagen synthesis (needed for corneal } \\
\text { stromal healing), protecting against corneal } \\
\text { ulceration and perforation }\end{array}$ & $1-2$ hourly \\
\hline Oral ascorbic acid & As above & $1 \mathrm{~g}$ twice a day \\
\hline $\begin{array}{l}\text { Sodium citrate } 10.11 \% \\
\text { eye drops }\end{array}$ & $\begin{array}{l}\text { Chelation of cations and preventing release of } \\
\text { proteolytic enzymes, preventing corneal melts/ } \\
\text { perforation. }\end{array}$ & 1-2 hourly \\
\hline Oral tetracycline & $\begin{array}{l}\text { Suppressing proteolytic enzymes and scavenging } \\
\text { free oxygen radicals release. Halting corneal } \\
\text { epithelial and stromal melts. }\end{array}$ & $\begin{array}{l}\text { Doxycycline } 100 \mathrm{mg} \text { once daily, or oxytetracycline } 500 \mathrm{mg} \\
\text { twice a day }\end{array}$ \\
\hline Cycloplegic eye drop & Mydriasis and pain relief & Topical PF cyclopentolate $1 \%, 2-3$ times a day \\
\hline Lubricating eye drops $(\mathrm{PF})$ & Prevents drying and promotes re-epithelialisation & Locally available PF eye drops, $1-2$ hourly \\
\hline IOP lowering therapy & Control raised intraocular pressure & $\begin{array}{l}\text { Treatment choice depends on level of ocular hypertension. } \\
\text { Early consultation with glaucoma team advised. }\end{array}$ \\
\hline
\end{tabular}

$P F$ preservative-free

${ }^{\text {a }}$ See references in respective sections below 
vicious cycle of further ocular tissue damage and an ongoing inflammatory response [52]. Alkali is both hydrophilic and lipophilic, with the hydroxyl ion enabling saponification of fatty acids in cell membranes and resultant cellular necrosis and disruption [25]. The inflammatory response generates further proteolytic enzyme release. These characteristics enable rapid and deep penetration of cell membranes (unlike acids) resulting in rapid corneal epithelium damage. Cations in the alkali cause hydration of glycosaminoglycans and collagen fibrils, resulting in loss of corneal clarity and thickening of the cornea [8, 25]. Intensive topical corticosteroids has for decades been one of the mainstays of treatment, and remains as such [53, 54]. The role of corticosteroids is of paramount importance in corneal stromal healing, as they reduce inflammatory cell infiltration, and reduce polymorphonuclear lysosomal enzyme release. They are also helpful in the treatment or prevention of associated iridocyclitis. In animal models of ocular chemical burns, an increased risk of corneal melting has been witnessed with use of corticosteroids for more than 6 days [53]. Despite this, two retrospective studies have shown no evidence of increased risk of corneo-scleral melting on the provision that there is concurrent use of ascorbate [24, 55]. We have not observed an increased risk of corneal melting with concurrent use of ascorbate in severe chemical corneal burns. Considering the critical role that inflammation plays in tissue necrosis and disruption, we advocate the immediate use of intensive topical corticosteroids for sufficient and timely inflammatory inhibition. A potent corticosteroid eye drop (e.g. dexamethasone $0.1 \%$ ) should be started from day one, and administered topically on a 1 or 2 hourly basis. For severe inflammation that in not controlled with topical intensive corticosteroids, systemic corticosteroids can be considered. Topical nonsteroidal antiinflammatory drugs (NSAIDs) are thought to be a risk factor for corneal melts in the presence of an epithelial defect (ED), and we therefore do not advocate their use in the acute stages or in the presence of an ED [56].

\section{Halting epithelial and stromal breakdown}

Inflammatory cell release of matrix metalloproteinases, collagenase and stromelysin cause collagen breakdown, which augment the toxic effect of the offending chemical on the corneal stroma resulting in corneal and scleral thinning/ melts [5]. There is strong evidence for the role of tetracyclines and citrate in suppressing the release of proteolytic enzymes and in scavenging free oxygen radicals release in animal models of chemical injuries [57]. Systemic tetracycline inhibits corneal ulceration in animal models of ocular chemical burns [58]. Topical citrate has also been shown to reduce the incidence of corneal perforation in animal models of severe chemical injury [59].
Tetracycline derivatives possess both anti-bacterial and antiinflammatory properties. Doxycycline downregulates the expression of CXCL8 and pro-inflammatory cytokines IL$1 \mathrm{~b}$ and TNF [57]. Doxycycline is also responsible for inhibiting MMP-9 activity and supports ocular surface integrity. Doxycycline has been reported to be effective in reducing ocular rosacea, dry eyes, and treatment of corneal abrasion [60, 61]. Systemic tetracyclines can also play a role in promoting repair non-healing corneal epithelial defects [57]. Based on these experimental models, most conventional medical therapy for acute chemical injuries includes an oral tetracycline (e.g. doxycycline $100 \mathrm{mg}$ once a day) and intensive topical sodium citrate drops (at least $4 \times /$ day).

\section{Promoting corneal re-epithelialisation}

Re-epithelialisation of the cornea is a key challenge in both the acute and chronic management of chemical ocular burns. In addition, chemical injuries can result in severe goblet cell and Meibomian gland dysfunction, resulting in mucin and oil deficiency of the tear film. Topical ocular lubricants are essential for maintaining a moisturised ocular surface that facilitates re-epithelialisation of the cornea [25]. Maintaining a moist ocular surface is also important to prevent the risk of further epithelial breakdown. It is important to use preservative-free lubricants to avoid further preservative-induced epitheliopathy.

Autologous peripheral blood serum (PBS), umbilical cord serum (UCS) and platelet rich plasma (PRP) have also been reported to accelerate epithelial healing in chemical ocular burns [62]. PBS and UCS contain various growth factors and essential tear components that are known to promote healing. The concentration of EGF, TGF- $\beta$ and NGF are several times higher in UCS than PBS, whilst Vitamin A and IGF-1 concentrations are higher in PBS [63]. It is not yet known whether these variations in concentrations have an additional therapeutic benefit, or indeed a detrimental impact. Both PBS and UCS have been used successfully for the treatment of severe dry eye syndrome, persistent epithelial defects and neurotrophic keratopathy [63, 64]. Interestingly, in a double-blind prospective RCT of patients with acute ocular burns of varying severity, eyes receiving UCS had a significantly lower mean time to complete re-epithelialisation, reduced limbal ischaemia and better corneal clarity than patients receiving autologous serum eye drops or artificial tears [65]. Although the trial was small, with 10, 11 and 12 patients in each group, these findings have been replicated in a mouse model of ocular chemical burn [66]. These topical treatments represent a possible armamentarium in managing epithelial healing, which is a major challenge in severe chemical injuries. They may also be a suitable alternative to amniotic membrane transplantation in some cases. Larger clinical trials are 
needed to more clearly elucidate this therapeutic benefit. Major obstacles to blood derived topical therapy are difficulties in obtaining and preparing the treatment, lack of a standardised preparation protocol, high cost and potential risk of contamination and infection [64]. At the present time, stored allogeneic serum drops are available within the United Kingdom, and can be ordered through NHS Blood and Transplant (NHSBT). Autologous serum drops can also be ordered through NHSBT (see Table 5), but the patient must be able to donate $400 \mathrm{ml}$ of blood, and be able to travel to a blood donation centre (correct as of January 2019). Furthermore, autologous donations are contraindicated in patients with serious cardiovascular disease or active bacterial infection. Patients with confirmed positive markers for transmissible infections (HIV, Hepatitis B, Hepatitis C, HTLV and Syphilis) are not eligible to donate.

Human amniotic membrane transplantation (AMT) is utilised in acute ocular chemical burns for supporting reepithelialisation of the ocular surface and reducing inflammation. However, there is a dearth of evidence of a significant role in reducing LSCD development or

Table 5 Current sources of non-locally available treatments of chemical eye burns in the UK

\begin{tabular}{|c|c|}
\hline Treatment & UK sources \\
\hline $\begin{array}{l}\text { Potassium ascorbate } 10 \% \\
\text { eye drops }\end{array}$ & $\begin{array}{l}\text { Stockport Pharmaceuticals } \\
\text { Tel: } 01614195666 \\
\text { Fax: } 01614195426 \\
\text { E-mail: sppu.orders@ stockport.nhs.uk } \\
\text { Tayside Pharmaceuticals } \\
\text { Tel: } 01382632052 \\
\text { Fax:01382632060 } \\
\text { E-mail: tpsales.Tayside@ nhs.net }\end{array}$ \\
\hline $\begin{array}{l}\text { Sodium citrate } 10.11 \% \\
\text { eye drops }\end{array}$ & $\begin{array}{l}\text { Mandeville Medicines } \\
\text { Tel: 01296394142 } \\
\text { Fax:01296397223 } \\
\text { E-mail: info@mandevillemedicines.com }\end{array}$ \\
\hline $\begin{array}{l}\text { Autologous or allogeneic } \\
\text { serum drops }\end{array}$ & $\begin{array}{l}\text { NHSBT Tissue and Eye Services } \\
\text { Tel: } 03000200113 \\
\text { Fax: } 08456076819 \\
\text { E-mail: asetears@nhsbt.nhs.uk }\end{array}$ \\
\hline $\begin{array}{l}\text { Amniotic membrane } \\
\text { (frozen) }\end{array}$ & $\begin{array}{l}\text { NHSBT Tissue and Eye Services } \\
\text { Tel: 08456076820 } \\
\text { Fax:08456076819 } \\
\text { E-mail: tscustserv@ nhsbt.nhs.uk }\end{array}$ \\
\hline Prokera ${ }^{\circledR}$ & $\begin{array}{l}\text { Scope Ophthalmics Ltd } \\
\text { Tel: } 08002700253 \\
\text { E-mail: info@scopeophthalmics.com }\end{array}$ \\
\hline Omnigen $^{\circledR}$ & $\begin{array}{l}\text { NuVision Biotherapies Ltd } \\
\text { Tel: } 01157840120 \\
\text { E-mail: orders@nu-vision.co.uk }\end{array}$ \\
\hline Holoclar $^{\circledast}$ & $\begin{array}{l}\text { Chiesi Ltd } \\
\text { Tel: } 01614885555 \\
\text { Fax:01614885566 } \\
\text { E-mail: info@ chiesi.uk.com }\end{array}$ \\
\hline Morgan lens ${ }^{\circledR}$ & https://www.morganlens.com/distributors \\
\hline
\end{tabular}

improving final visual outcome in very severe chemical burns [33, 67, 68]. A systematic review of acute ocular burns found only one RCT (not blinded) comparing AMT and conventional medical therapy (CMT) to CMT alone [69]. Re-epithelialisation rate was significantly faster in the AMT group in medium severity ocular injuries (Dua et al. grades II-III) [34].

More recently, a randomized, parallel-controlled clinical trial compared CMT (30 eyes of 30 patients) to CMT combined with AMT (30 eyes of 30 patients) for treatment of acute severe chemical burns. Mean follow-up time was 20.3 months. No statistically significant difference was detected in mean corneal epithelial defect healing time, mean BCVA achieved nor in central corneal vascularisation [70]. It is important to note that this study only included the most severe chemical injuries (Roper-Hall grade IV), with extensive limbal ischaemia. The study findings cast further doubt on the controversial role of AMT in the management of acute severe chemical burns.

There are three main forms of amniotic membrane available for use in the UK:

1. Cryopreserved amniotic membrane (most commonly used, available from NHSBT).

2. Freeze dried amniotic membrane (easier to access/ store).

3. Sutureless amniotic membrane.

Conventional cryopreserved (frozen) amniotic membrane has been studied extensively, and is known to have antiinflammatory, anti-fibrotic, anti-angiogenic and anti-microbial properties [71]. Mechanically, it acts as a scaffold, enabling adhesion and migration of epithelial cells. Freeze dried amniotic membrane, on the other hand, does not appear to significantly compromise the biochemical or structural properties of AM as compared with cryopreserved AM, particularly when pre-treated with trehalose or raffinose [71, 72]. It has the advantages of being stable, enabling it to be transported and stored at room temperature. This may be advantageous, particularly in the developing world, or areas of reduced accessibility to healthcare.

One of the barriers to use of amniotic membranes is the extensive suturing required to apply it onto the ocular surface. Advances have been made in sutureless amnion technology. Prokera ${ }^{\circledR}$ is one such device, designed by clipping a piece of amniotic membrane between two rings made from a clear, flexible material. In one study, Prokera was found to have complete or partial success in treating nonhealing corneal ulcers of $80 \%$ of chemically injured eyes [73]. Other new amnion based devices include Omnigen a transportable amniotic membrane derived biological matrix. It is dry and has no viable cells, and hence be used straight from a sterile pack stored at room temperature. 
It can therefore be accessed rapidly when required. If used with OmniLenz ${ }^{\circledast}$, it can be applied to the eye like a contact lens, eliminating the need for sutures. There are no robust clinical trials comparing efficacy and safety of different forms of amniotic membranes.

In addition to AMT, Tenon's tissue advancement has been utilised for cases of limbal ischaemia with resultant anterior segment necrosis and corneo-scleral melts. This aim of this procedure is to re-establish limbal vascularity. It can be a single early stage procedure, or combined with AMT. Anterior segment fluorescein angiography maybe considered to enable more selective localised tenonplasty [74]. It must be noted that Tenon advancement procedures are difficult in patients with acute injury due to the presence of friable and inflamed conjunctiva and Tenon's tissue.

More recently proposed modalities for wound healing include corneal collagen cross-linking, subconjunctival TNF- $\alpha$ antibodies (Infliximab), regenerative agent (Cacicol20, Paris, France) and growth factors (e.g. fibronectin, EGF, retinoic acid). They have all been shown to promote re-epithelialisation of the ocular surface in animal models of alkali chemical burns [62, 75-77]. These therapies are still awaiting clinical trials in humans to determine their efficacy.

There are some data on the role of early limbal stem cell transplantation in acute burns which shows that outcome relies upon limbal vascularity [78]. The main issue in early limbal stem cell failure with epithelial defects is limbal ischaemia. Repeated amniotic membrane transplantation maybe of major benefit in management of early epithelial defects in this setting. Restoring limbal vascularisation and resolution of ocular surface inflammation are important factors for viability and function of transplanted limbal stem cells.

Finally, as with persistent corneal epithelial defects due to a variety of other causes, a number of strategies can aid the epithelial healing process. Punctal plugs to reduce tear drainage helps minimise ocular surface dryness, particularly in patients with aqueous tear deficiency. A soft contact lens, of which the diameter should be wider than the limbal diameter, serves to protect the corneal surface from direct eyelid mechanical rubbing. It is important that the contact lens is well-fitted, to avoid further mechanical irritation. Botulinum toxin injection and tarsorrhaphy serve a similar purpose in terms of minimising mechanical rubbing against the healing corneal epithelial cells. They have the additional benefit of being more effective than a soft BCL in reducing ocular surface exposure, which also aids epithelial healing. In addition, the increased risk of microbial keratitis associated with contact lens use is avoided. In more resistant cases of persistent epithelial defects, fitting a scleral contact lens can be tried. This may aid re-epithelialisation in two ways, by protecting against mechanical eyelid rubbing, and by providing a hydrating reservoir of fluid between the contact lens and corneal surface.

\section{Promoting corneal stromal healing}

Potent alkali agents can rapidly penetrate into anterior chamber, increasing the $\mathrm{pH}$ of aqueous humour and inflicting severe ciliary body damage [79]. As well as causing potentially severe recalcitrant hypotony, this can result in decreased ciliary body ascorbate secretion. Ascorbate is an essential co-factor for stromal collagen healing and maintenance of corneal clarity [80]. Significant reduction of ascorbate levels in aqueous humour is known to occur after chemical injuries, which can in turn inhibit collagen synthesis by fibroblasts [81, 82]. Ascorbate deficiency thus increases the risk of corneal ulceration, descemetoceles and perforation [83, 84]. Corneal ulceration and perforation incidence have been shown to decrease with immediate treatment with ascorbate.

Treatment with ascorbate can be both topical and/or systemic. Topical ascorbate has better anterior segment penetration than oral ascorbate [81, 85]. Compliance with topical ascorbate eye drops is can be a challenge due to ocular pain on instillation of drops. A recent study showed that $33 \%$ of patients with severe ocular chemical burns did not comply with topical ascorbate and citrate drops [18]. We therefore advocate the concurrent use of oral ascorbate in all severe chemical burns, low threshold for admission, and importance of educating patients re importance of drops even if they cause pain.

Combined ascorbate/citrate treatment appears to offer more protection against ulceration than citrate alone [86]. In an 11-year retrospective nonrandomized comparative study, use of intensive treatment with ascorbate and citrate regimen was shown to be of benefit for patients with Roper-Hall grade III burns [24]. The clinical benefit due to each agent is not quantifiable as was not compared with other treatment regimens.

\section{Management of chronic complications}

\section{Limbal stem cell transplantation}

A devastating complication of severe chemical eye burns is limbal stem cell deficiency (LSCD). This condition results from irreversible damage to limbal stem cells situated in a deep and protected microenvironment within the limbal epithelium. LSCD manifests as corneal conjunctivalisation, corneal vascularisation, chronic inflammation and recurrent or persistent corneal epithelial defects. Re-epithelialisation can be further hampered by a chronically dry ocular surface because of goblet cell and Meibomian gland dysfunction. 
Progressive conjunctival cicatrisation also impedes re-epithelialisation, not least by the resultant mechanical irritation. Cicatricial changes include fornix shortening, symblepharon/ankyloblepharon formation, trichiasis and subtarsal scarring. Specialist adnexal input is helpful for management of these complications.

Optimising the ocular surface before LSCT by management of pre-existing conditions such as aqueous tear deficiency and lagophthalmos is paramount. Any lid abnormalities (e.g. cicatrisation, entropion, trichiasis) increasing risk of graft failure should be addressed in the first instance. Other measures to eliminate mechanical irritation, such as fornix reconstruction and symblephara lysis, if needed, should also be performed prior to any LSCT. The LSCT should only be done once the inflammation has subsided for at least 3 months. These measures are not only important for the survival of limbal stem cell transplanted tissue, but also for aiding in the recovery of existing stem cells damaged by chemical injury. In general, LSCTs are either autologous or allogeneic, and are either biopsies of limbal tissue or culture-expanded cells.

Partial LSCD requires treatment if there is central corneal involvement affecting vision. Pannus resection combined with limbal stem cell transplantation (LSCT) enables reepithelialisation of the cornea with corneal epithelial cells. A recent study showed that pannus resection with AMT maybe an equally good alternative to LSCT for the management of partial LSCD [87].

For total unilateral LSCD, limbal stem cells can be harvested from the patient's other eye as part of a conjunctival-limbal autograft (CLAU) procedure or can be used for ex vivo cultivated limbal epithelial transplantation (CLET). A more novel technique called simple limbal epithelial transplantation (SLET) has also been described. In SLET, direct transplantation of a tiny limbal fragment from the unaffected eye was found to be sufficient for reversing LSCD, negating the need for ex vivo expansion [88]. The limbal fragment $(2 \mathrm{~mm} \times 2 \mathrm{~mm})$ is divided into 8-10 smaller fragments which are evenly distributed onto an amniotic membrane and transplanted to the contralateral eye. It can be performed as a primary procedure in LSCD. In cases in which CLET has failed, SLET has been proposed as an alternative option to repeat CLET [89]. Longterm studies are awaited to confirm that corneal conjunctivalisation does not recur in between the areas of limbal fragments transplantation.

In ocular chemical burns, CLAU has excellent outcomes. It results in corneal vascularisation regression, corneal reepithelialisation and improved vision in around $75-81 \%$ of patients after 1 year [90]. After 3 years, this is around $70 \%$. The theoretical risk of inducing LSCD in the healthy eye has not yet been substantiated [91]. Similar clinical outcomes have been achieved with SLET and with CLET in chemical injuries, however, long-term follow-up results for SLET are awaited [92].

In patients with bilateral LSCD, limbal stem cells may be harvested from immediate family members as a livingrelated conjunctival-limbal allograft (lr-CLAL), cadaveric eyes as a keratolimbal allograft (KLAL) or allogenic cultivated limbal epithelial transplantation (allo-CLET) [93, 94]. These allogeneic transplants obviously require systemic immune suppression. Other options include cultivated oral mucosal epithelial transplantation (COMET), which allows a penetrating keratoplasty at a later stage to improve vision and ocular surface [95]. Keratolimbal transplants for patients with chemical injury induced total LSCD and dense corneal scarring have been reported to have a 3.4 year mean graft survival time [96]. This is a procedure in which an eccentric trephination of the donor button enables simultaneous transplantation of full thickness corneal graft and limbal stem cells. For CLAL the largest studies show that $50 \%$ of eyes achieved post-operative BCVA $\geq 20 / 200$. A recent systemic review looked at studies in which KLAL was done for chemical injury induced total LSCD. Eightynine percent underwent simultaneous or subsequent penetrating keratoplasty [94]. Median follow-up for 29 eyes was 42 months (range: 6.2-114 months), and 69\% had BCVA $\geq 20 / 200$ at last follow-up. Considering the poor prognosis of total LSCD, these results are encouraging. Similar BCVA results (mean follow-up of 4.8 years) have been achieved for allogeneic cultivated limbal epithelial transplantation with or without subsequent penetrating keratoplasty [97]. Encouraging results have also been reported in a small study looking at the early outcomes for penetrating keratoplasty following SLET [98]. A recently published study looked at the outcome of PKP in 14 patients who previously underwent COMET [95]. BCVA improved significantly, from $2.67 \pm 0.08 \mathrm{LogMAR}$ preoperatively to $0.64 \pm 0.27$ LogMAR after PKP (mean follow-up 28.2 \pm 8 months). Although trials with larger patient numbers and longer follow-up are needed, these results are promising. COMET has also been utilised in patients with persistent epithelial defects and ocular inflammation, enabling reepithelialisation and stabilisation of the ocular surface [99].

More long-term data were recently published in a study that included 165 eyes of 110 patients with LSCD due to a multitude of causes $(20.6 \%$ due to chemical/thermal injuries). This retrospective study looked at long-term outcome of limbal stem cell allograft transplantation requiring systemic immunosuppression [100]. Patients underwent KLAL, lr-CLAL, combined KLAL/lr-CLAL, or combined KLAL/CLAU. Mean follow-up was 9.1 years (range: 5.2-17.7 years). In other words, the minimum follow-up was more than 5 years. At last follow-up, there was $\geq 2$ lines BCVA improvement in $62.1 \%$, whilst BCVA reduced in $18.6 \%$. Ocular surface stability was achieved in $72.7 \%$. 
Additional limbal stem cell allograft transplantation was necessary in $30.9 \%$ (51/165 eyes) to maintain ocular surface stability. In the subgroup of patients with chemical/thermal injuries, a gain of 2 or more lines of BCVA was achieved in $76.5 \%$, and ocular surface stability was achieved in $70.3 \%$. It is also worthy of note that this subgroup of patients did significantly better than patients with Steven-Johnsons syndrome or mucus membrane pemphigoid.

The most common cause of ocular surface failure following LSCT is graft rejection, accounting for about $75 \%$ of cases [100]. The limbus is highly vascular and rejection can therefore be aggressive. Other causes include ocular surface exposure, mechanical irritation (e.g. trichiasis/entropion) infection and graft failure. This highlights the importance of adequate immunosuppression to minimise rejection risk. There is no universally agreed regimen for topical and systemic immunosuppression. Systemic regimens commonly used include systemic corticosteroids combined with a steroid-sparing agent, commonly cyclosporine [94]. Others prefer more aggressive systemic immunosuppression, combining systemic corticosteroids with dual immunosuppressives, such as cyclosporine and azathioprine, or tacrolimus and mycophenolate mofetil [100]. The mainstay of topical immunosuppression is steroid eye drops, with some authors also using topical cyclosporine [94, 100]. It is important for the treating ophthalmologist to be experienced in the use of potent systemic immunosuppression, and it is preferable to work alongside a physician with expertise in immunosuppression for organ transplantation. This will facilitate maximising efficacy of immunosupressives used, and careful monitoring of systemic side effects.

In many countries, including Europe, India and Japan, both biopsy-based keratolimbal transplantation and cell culture-based transplantation are permitted for use. Only the former, however, is licenced and allowed by the Food and Drug Administration (FDA) in the United States. More recently, the Holoclar ${ }^{\circledast}$ has been licenced in Europe for management of moderate to severe LSCD [101]. This is a transparent circular sheet composed of ex vivo expanded autologous human corneal epithelial cells (including limbal stem cells), attached on a supportive $2.2 \mathrm{~cm}$ diameter fibrin layer and maintained in the transport medium. In the UK it is licensed for transplantation to eyes with moderate to severe LSCD (defined as presence of superficial corneal neovascularisation in at least two corneal quadrants, with central corneal involvement, and severely impaired visual acuity) [102]. To qualify for treatment, patients must meet the criteria set by NICE: it is used to treat one eye only, and has already had a conjunctival-limbal autograft, or there is insufficient tissue for a conjunctival-limbal autograft or it is contraindicated, and the company provides a discount agreed in the patient access scheme. Bilateral treatment can only be done in the context of research. According to the company's submission, a single treatment for one eye costs $£ 80,000$ excluding VAT. The company has agreed a patient access scheme with the Department of Health. The level of the discount is commercial in confidence [102].

\section{Keratoplasty and keratoprosthesis}

Another important aspect of chronic management is the consideration of corneal transplantation. Both penetrating keratoplasty (PKP) and deep anterior lamellar keratoplasty (DALK) can be performed in vision-limiting corneal scarring. Anterior lamellar keratoplasty is preferred when possible, to reduce the risk of rejection. This risk is already high in an eye prone to inflammation and vascularisation. Systemic immunosuppression should be considered for eyes with increased risk of rejection. Keratoplasty should only be contemplated once limbal stem cell function has normalised. In LSCD, a staged procedure, where the limbal stem cell transplant occurs at least 6 weeks prior to corneal transplantation, is associated with $80 \%$ survival rate after 12 months. This is in sharp contrast to $25 \%$ success rate for non-staged procedures [45]. The median survival for combined limbal stem cell transplant and keratoplasty is 1 year, whilst it is 4 years for a staged procedure [45]. The success rate of PKP following different types of LSCT was discussed in the LSCT section.

In recurrent failure of penetrating keratoplasty, the Boston Type 1 Keratoprosthesis can be considered. A recent systemic review of Boston Type 1 Keratoprosthesis implantation in chemical injuries looked at visual outcomes and keratoprosthesis retention [103]. Although no RCTs were found, a total of nine studies looked at a pool of 106 eyes of 100 patients. BCVA of 20/200 or better was achieved and retained in more than $64.1 \%$ of chemical injuries at 2 years follow-up, from a median pre-operative BCVA of hand movements (HM). However, three of the nine studies had $<1$ year follow-up, which may have skewed the visual outcome results knowing that complications accrue over time. Neverless, the visual improvement rates, and the fact that systemic immunosuppression can be spared is encouraging. The keratoprosthesis retention rate was $88.9 \%$. Interestingly, the most common cause of BCVA $<20 / 200$ was glaucoma, once again emphasising the importance of glaucoma specialist input.

The osteo-odonto keratoprosthesis (OOKP) remains the treatment of choice in end-stage corneal disease not amenable to aforementioned keratoplasty options. OOKP is particularly resilient in a dry keratinised eye following chemical injury. Ocular surface exposure, number of previous failed PKP's and presence of autoimmune disease are risk factors for failure [104]. A recent study of OOKP in chemical/thermal burns reported that although anatomic success is high in such patients, the visual potential is often limited by glaucomatous optic neuropathy [105]. Moreover, a fair number of these patients require glaucoma shunt procedures. Endophthalmitis 
rates are also higher than usually observed in corneal or intraocular surgery. All of these observations mirror findings of previous studies [106]. It is imperative therefore that patients with Boston Type 1 Keratoprosthesis or OOKP are closely monitored for glaucoma, and preferably co-managed by an experienced glaucoma team. We also advocate warning patients undergoing OOKP about the potentially increased risk of endophthalmitis.

\section{Intraocular pressure (IOP) and glaucoma}

Severe chemical burns which damage the corneal architecture can result in distortion of the trabecular meshwork (TM), leading to intraocular pressure (IOP) elevation. As well as direct TM damage by the alkali, inflammatory debris deposition at the TM can also contribute to increased IOP. Episcleral vasculopathy can result in further hindrance to aqueous outflow. There is a high incidence of glaucoma after severe ocular chemical injury [107-109]. In a study of 90 eyes of 66 patients with severe chemical injuries, 14 eyes (15.6\%) developed early secondary glaucoma, and 20 eyes (22.3\%) developed late secondary glaucoma [110]. Rates of advanced glaucoma limiting visual potential in patients with Boston Type 1 Keratoprosthesis, or OOKP are even higher $[3,111]$. Hence, it is important not to neglect regular monitoring of the IOP and for glaucoma development. This can be overlooked when clinicians are focused on evaluating and treating the ocular surface over the long term. The IOP can be abnormally elevated or decreased, and can change with time from one state to another. Raised IOP can have multifactorial causes (e.g. TM damage/obstruction, episcleral venous damage). Therefore, it may be more resistant to standard topical therapy (e.g. IOP lowering eye drops). Cicatrisation of the conjunctiva and underlying structures results in understandably low success rates for trabeculectomy surgery. Glaucoma tube surgery is therefore more common, but these cases are often challenging with significant rates of revision [112]. Cyclophotocoagulation maybe more effective than various IOP lowering interventions for refractory glaucoma [107], but risks further conjunctival inflammation and scarring. To the best of our knowledge, no prospective comparative trials of IOP lowering interventions in severe chemical injuries have been performed. Although management is complex, good longterm IOP control is achievable [112]. Therefore if IOP is not optimally controlled, early referral to a specialist glaucoma service is highly advocated.

\section{Conclusions}

Chemical eye burns are frequently encountered in emergency departments. Causes include domestic accidents, workplace-related injuries and assaults. There are several important interventions to be made in the management of chemical eye injuries: public health messages regarding prevention and the importance of immediate eye irrigation following burns, early assessment and treatment by an ophthalmologist and the development of novel treatments for ocular surface reconstruction (such as stem cell therapies).

Despite several decades of research and public health initiatives, simple and effective interventions such as wearing protective eyewear and immediate irrigation of eyes remain as key challenges [113]. Most serious chemical eye injuries are work-related [111]. Many workrelated eye injuries occur in those not wearing protective eyewear at the time, and such protective eyewear reduces the odds of eye injury $[3,111]$. A recent increase in crimerelated chemical injuries in the UK [16] further emphasises the importance of public education in first-aid management of such chemical burns. There have been widespread media campaigns to educate the public about early irrigation, however, more is required to protect people in the workplace [16]. Current legislation, overseen by the Health and Safety Executive, does not compel employers to provide additional training and first-aid equipment where there is a higher risk of contact with chemicals [114]. A change in legislation may be effective in reducing the incidence of chemical burns in hazardous occupations and help in raising awareness about the importance of immediate eye irrigation. We also propose a collective approach to collecting hospital data on chemical eye burns, their treatment and outcomes.

Challenges in the management of severe ocular burns include reduced adherence to treatment amongst a younger population group, pain associated with certain treatments (e.g. ascorbate drops) and poor follow-up rates [18]. Better communication with patients and their relatives, relaying the importance of compliance with treatment (despite intensive regimens and associated pain) and follow-up attendance is essential. In the acute stages, admission of severe cases of ocular chemical burns may be a better management option than outpatient visits.

Over the past decades, advances in ocular surface reconstruction such as the use of cultured cell therapies have improved outcomes for patients with limbal stem cell deficiency. These treatments can be effective in severe chemical eye burns, even decades after the initial injury. Patients should be referred to tertiary care centres for consideration of such treatments.

\section{Compliance with ethical standards}

Conflict of interest The authors declare that they have no conflict of interest. 
Publisher's note: Springer Nature remains neutral with regard to jurisdictional claims in published maps and institutional affiliations.

\section{References}

1. McCulley JP. Chemical injuries. In: Smolin G, Thoft RA, editors. The cornea: scientific foundation and clinical practice. Boston Mass: Little Brown and Co1987. p. 527-42.

2. Xiang H, Stallones L, Chen G, Smith GA. Work-related eye injuries treated in hospital emergency departments in the US. Am J Ind Med. 2005;48:57-62.

3. Yu TSI, Liu H, Hui K. A case-control study of eye injuries in the workplace in Hong Kong. Ophthalmology. 2004;111:70-4.

4. Kuckelkorn R, Kottek A, Schrage N, Reim M. Poor prognosis of severe chemical and thermal eye burns: the need for adequate emergency care and primary prevention. Int Arch Occup Environ Health. 1995;67:281-4.

5. Reim M, Bahrke C, Kuckelkorn R, Kuwert T. Investigation of enzyme activities in severe burns of the anterior eye segment. Graefes Arch Clin Exp Ophthalmol. 1993;231:308-12.

6. Xie Y, Tan Y, Tang S. Epidemiology of 377 patients with chemical burns in Guangdong province. Burns. 2004;30:569-72.

7. Haring RS, Sheffield ID, Channa R, Canner JK, Schneider EB. Epidemiologic trends of chemical ocular burns in the United States. JAMA Ophthalmol. 2016;134:1119-24.

8. Adepoju FG, Adeboye A, Adigun IA. Chemical eye injuries: presentation and management difficulties. Ann Afr Med. 2007;6:7-11.

9. Hong J, Qiu T, Wei A, Sun X, Xu J. Clinical characteristics and visual outcome of severe ocular chemical injuries in Shanghai. Ophthalmology. 2010;117:2268-72.

10. Morgan SJ. Chemical burns of the eye: causes and management. Br J Ophthalmol. 1987;71:854-7.

11. Macdonald EC, Cauchi PA, Azuara-Blanco A, Foot B. Surveillance of severe chemical corneal injuries in the $\mathrm{UK}$. Br J Ophthalmol. 2009;93:1177-80.

12. White ML, Chodosh J, Jang J, Dohlman C. Incidence of StevensJohnson syndrome and chemical burns to the eye. Cornea. 2015;34:1527-33

13. Ghosh S, Salvador-Culla B, Kotagiri A, Pushpoth S, Tey A, Johnson ZK, et al. Acute chemical eye injury and limbal stem cell deficiency-a prospective study in the United Kingdom. Cornea. 2019;38:8-12.

14. Beare JD. Eye injuries from assault with chemicals. Br J Ophthalmol. 1990;74:514-8.

15. O'Driscoll AM, Aggarwal RK, Shah P, Chell PB, Hope-Ross MW, McDonnell PJ. Ocular injuries due to alkaline substances. Brit Med J. 1995;310:943.

16. Miller R, Pywell S, Leon-Villapalos J, Atkins J. Chemical burn assaults: is the media coverage representative? Burns: J Int Soc Burn Inj. 2018;44:1021-2.

17. Saini JS, Sharma A. Ocular chemical burns-clinical and demographic profile. Burns. 1993;19:67-9.

18. Bizrah M, Yusuf A, Ahmad S. Adherence to treatment and followup in patients with severe chemical eye burns. Ophthalmol Ther. 2019;8 https://doi.org/10.1007/s40123-019-0173-y.

19. Ratnapalan S, Das L. Causes of eye burns in children. Pedia Emerg Care. 2011;27:151-6.

20. D'Cruz R, Pang TCY, Harvey JG, Holland AJA. Chemical burns in children: Aetiology and prevention. Burns: J Int Soc Burn Inj. 2015;41:764-9.

21. Breazzano MP, Day HR, Tanaka S, Tran U. Prospective analysis of pediatric ocular chemical burns: laundry detergent pods. J Aapos. 2018;22:426-8.
22. Mathew RG, Kennedy K, Corbett MC. Eyes and alkalis. Wave of paediatric eye injuries from liquid detergent capsules. BMJ (Clin Res ed). 2010;340:c1186.

23. Vajpayee RB, Shekhar H, Sharma N, Jhanji V. Demographic and clinical profile of ocular chemical injuries in the pediatric age group. Ophthalmology. 2014;121:377-80.

24. Brodovsky SC, McCarty CA, Snibson G, Loughnan M, Sullivan L, Daniell M, et al. Management of alkali burns: an 11-year retrospective review. Ophthalmology. 2000;107:1829-35.

25. Wagoner MD. Chemical injuries of the eye: current concepts in pathophysiology and therapy. Surv Ophthalmol. 1997;41:275-313.

26. Hughes WF Jr. Alkali burns of the eye; clinical and pathologic course. Arch Ophthal. 1946;36:189-214.

27. Friedenwald JS, Hughes WF Jr., Herrmann H. Acid burns of the eye. Arch Ophthal. 1946;35:98-108.

28. Grant WM, Thomas CC. Toxicology of the eye, third edition. J Toxicol: Cutan Ocul Toxicol. 1987;6:155-6.

29. Schultz G, Henkind P, Gross EM. Acid burns of the eye. Am J Ophthalmol. 1968;66:654-7.

30. McCulley JP. Ocular hydrofluoric acid burns: animal model, mechanism of injury and therapy. Trans Am Ophthalmol Soc. 1990;88:649-84.

31. Roper-Hall MJ. Thermal and chemical burns. Trans Ophthalmol Soc UK. 1965;85:631-53.

32. Ballen PH. Treatment of chemical burns of the eye. Eye Ear Nose Throat Mon. 1964;43:57-61.

33. Tamhane A, Vajpayee RB, Biswas NR, Pandey RM, Sharma N, Titiyal JS, et al. Evaluation of amniotic membrane transplantation as an adjunct to medical therapy as compared with medical therapy alone in acute ocular burns. Ophthalmology. 2005; 112:1963-9.

34. Tandon R, Gupta N, Kalaivani M, Sharma N, Titiyal JS, Vajpayee RB. Amniotic membrane transplantation as an adjunct to medical therapy in acute ocular burns. Brit J Ophthalmol. 2011;95:199-204.

35. Gupta N, Kalaivani M, Tandon R. Comparison of prognostic value of Roper Hall and Dua classification systems in acute ocular burns. Br J Ophthalmol. 2011;95:194-8.

36. Dua HS, King AJ, Joseph A. A new classification of ocular surface burns. Br J Ophthalmol. 2001;85:1379-83.

37. Gupta N, Kalaivani M, Tandon R. Comparison of prognostic value of Roper Hall and Dua classification systems in acute ocular burns. Br J Ophthalmol. 2011;95:194-8.

38. Westekemper H, Figueiredo FC, Siah WF, Wagner N, Steuhl K$\mathrm{P}$, Meller D. Clinical outcomes of amniotic membrane transplantation in the management of acute ocular chemical injury. $\mathrm{Br}$ J Ophthalmol. 2017;101:103-7.

39. Kam KW, Patel CN, Nikpoor N, Yu M, Basu S. Limbal ischemia: reliability of clinical assessment and implications in the management of ocular burns. Indian $\mathrm{J}$ Ophthalmol. 2019;67:32-6.

40. Spöler F, Först M, Kurz H, Frentz M, Schrage NF. Dynamic analysis of chemical eye burns using high-resolution optical coherence tomography. J Biomed Opt. 2007;12:041203.

41. Tsoulnaras KI, Liakopoulos DA, Grentzelos MA, Pallikaris AI, Mikropoulos DG, Kymionis GD. Confocal Microscopy and Anterior segment optical coherence tomography findings after chemical alkali corneal burn. Cornea. 2016;35:e32-5.

42. Gerard M, Louis V, Merle H, Josset P, Menerath JM, Blomet J. Experimental study about intra-ocular penetration of ammonia. J Fr Ophtalmol. 1999;22:1047-53.

43. Rihawi S, Frentz M, Becker J, Reim M, Schrage NF. The consequences of delayed intervention when treating chemical eye burns. Graefes Arch Clin Exp Ophthalmol. 2007;245:1507-13.

44. Moon ME, Robertson IF. Retrospective study of alkali burns of the eye. Aust J Ophthalmol. 1983;11:281-6. 
45. Baradaran-Rafii A, Eslani M, Haq Z, Shirzadeh E, Huvard MJ, Djalilian AR. Current and upcoming therapies for ocular surface chemical injuries. Ocul Surf. 2017;15:48-64.

46. Ikeda N, Hayasaka S, Hayasaka Y, Watanabe K. Alkali burns of the eye: effect of immediate copious irrigation with tap water on their severity. Ophthalmologica. 2006;220:225-8.

47. Burns FR, Paterson CA. Prompt irrigation of chemical eye injuries may avert severe damage. Occup Health Saf. 1989;58:33-6.

48. Kuckelkorn R, Schrage N, Keller G, Redbrake C. Emergency treatment of chemical and thermal eye burns. Acta Ophthalmol Scand. 2002;80:4-10.

49. Kompa S, Schareck B, Tympner J, Wustemeyer H, Schrage NF. Comparison of emergency eye-wash products in burned porcine eyes. Graefes Arch Clin Exp Ophthalmol. 2002;240:308-13.

50. Rihawi S, Frentz M, Schrage NF. Emergency treatment of eye burns: which rinsing solution should we choose? Graefes Arch Clin Exp Ophthalmol. 2006;244:845-54.

51. Merle H, Donnio A, Ayeboua L, Michel F, Thomas F, Ketterle J, et al. Alkali ocular burns in Martinique (French West Indies) Evaluation of the use of an amphoteric solution as the rinsing product. Burns. 2005;31:205-11.

52. Paschalis EI, Zhou C, Lei F, Scott N, Kapoulea V, Robert MC, et al. Mechanisms of retinal damage after ocular alkali burns. Am J Pathol. 2017;187:1327-42.

53. Donshik PC, Berman MB, Dohlman CH, Gage J, Rose J. Effect of topical corticosteroids on ulceration in alkali-burned corneas. Arch Ophthalmol. 1978;96:2117-20.

54. Leibowitz HM. Management of inflammation in the cornea and conjunctiva. Ophthalmology. 1980;87:753-8.

55. Davis AR, Ali QH, Aclimandos WA, Hunter PA. Topical steroid use in the treatment of ocular alkali burns. Brit J Ophthalmol. 1997;81:732-4.

56. Hoffman RS, Braga-Mele R, Donaldson K, Emerick G, Henderson B, Kahook M, et al. Cataract surgery and nonsteroidal antiinflammatory drugs. J Cataract Refract Surg. 2016;42:1368-79.

57. Ralph RA. Tetracyclines and the treatment of corneal stromal ulceration: a review. Cornea. 2000;19:274-7.

58. Seedor JA, Perry HD, McNamara TF, Golub LM, Buxton DF, Guthrie DS. Systemic tetracycline treatment of alkali-induced corneal ulceration in rabbits. Arch Ophthalmol. 1987;105:268-71.

59. Pfister RR, Haddox JL, Lank KM. Citrate or ascorbate/citrate treatment of established corneal ulcers in the alkali-injured rabbit eye. Invest Ophthalmol Vis Sci. 1988;29:1110-5.

60. Solomon A, Rosenblatt M, Li D, Monroy D, Ji Z, Lokeshwar BL, et al. Doxycycline inhibition of interleukin-1 in the corneal epithelium. Am J Ophthalmol. 2000;130:688.

61. Hope-Ross MW, Chell PB, Kervick GN, McDonnell PJ, Jones HS. Oral tetracycline in the treatment of recurrent corneal erosions. Eye. 1994;8(Pt 4):384-8.

62. Sharma N, Kaur M, Agarwal T, Sangwan VS, Vajpayee RB. Treatment of acute ocular chemical burns. Surv Ophthalmol. 2018:63:214-35.

63. Yoon KC, Heo H, Im SK, You IC, Kim YH, Park YG. Comparison of autologous serum and umbilical cord serum eye drops for dry eye syndrome. Am J Ophthalmol. 2007;144:86-92.

64. Soni NG, Jeng BH. Blood-derived topical therapy for ocular surface diseases. Br J Ophthalmol. 2016;100:22-7.

65. Sharma N, Goel M, Velpandian T, Titiyal JS, Tandon R, Vajpayee RB. Evaluation of umbilical cord serum therapy in acute ocular chemical burns. Invest Ophthalmol Vis Sci. 2011;52:1087-92.

66. Oh HJ, Jang JY, Li Z, Park SH, Yoon KC. Effects of umbilical cord serum eye drops in a mouse model of ocular chemical burn. Curr Eye Res. 2012;37:1084-90.

67. Sharma N, Singh D, Maharana PK, Kriplani A, Velpandian T, Pandey RM, et al. Comparison of amniotic membrane transplantation and umbilical cord serum in acute ocular chemical burns: a randomized controlled trial. Am J Ophthalmol. 2016; 168:157-63.

68. Westekemper H, Figueiredo FC, Siah WF, Wagner N, Steuhl KP, Meller D. Clinical outcomes of amniotic membrane transplantation in the management of acute ocular chemical injury. Brit J Ophthalmol. 2017;101:103-7.

69. Clare G, Suleman H, Bunce C, Dua H. Amniotic membrane transplantation for acute ocular burns. Cochrane Db Syst Rev. 2012:CD009379 https://doi.org/10.1002/14651858.CD009379. pub2.

70. Eslani M, Baradaran-Rafii A, Cheung AY, Kurji KH, Hasani H, Djalilian AR, et al. Amniotic membrane transplantation in acute severe ocular chemical injury: a randomized clinical trial. Am J Ophthalmol. 2019;199:209-15.

71. Allen CL, Clare G, Stewart EA, Branch MJ, McIntosh OD, Dadhwal M, et al. Augmented dried versus cryopreserved amniotic membrane as an ocular surface dressing. PLoS ONE. 2013;8:e78441.

72. Paolin A, Trojan D, Leonardi A, Mellone S, Volpe A, Orlandi A, et al. Cytokine expression and ultrastructural alterations in freshfrozen, freeze-dried and $\gamma$-irradiated human amniotic membranes. Cell Tissue Bank. 2016;17:399-406.

73. Suri K, Kosker M, Raber IM, Hammersmith KM, Nagra PK, Ayres BD, et al. Sutureless amniotic membrane ProKera for ocular surface disorders: short-term results. Eye Contact Lens. 2013;39:341-7.

74. Tabatabaei SA, Soleimani M, Mirshahi R, Zandian M, Ghasemi $\mathrm{H}$, Hashemian MN, et al. Selective localized tenonplasty for corneal burns based on the findings of ocular surface fluorescein angiography. Cornea. 2017;36:1014-7.

75. Subasi S, Altintas O, Yardimoglu M, Yazir Y, Karaman S, Rencber SF, et al. Comparison of Collagen cross-linking and amniotic membrane transplantation in an experimental alkali burn rabbit model. Cornea. 2017;36:1106-15.

76. Zhou C, Robert MC, Kapoulea V, Lei F, Stagner AM, Jakobiec FA, et al. Sustained subconjunctival delivery of infliximab protects the cornea and retina following alkali burn to the eye. Invest Ophthalmol Vis Sci. 2017;58:96-105.

77. Cejkova J, Olmiere C, Cejka C, Trosan P, Holan V. The healing of alkali-injured cornea is stimulated by a novel matrix regenerating agent (RGTA, CACICOL20): a biopolymer mimicking heparan sulfates reducing proteolytic, oxidative and nitrosative damage. Histol Histopathol. 2014;29:457-78.

78. Rao SK, Rajagopal R, Sitalakshmi G, Padmanabhan P. Limbal autografting: comparison of results in the acute and chronic phases of ocular surface burns. Cornea. 1999;18:164-71.

79. Paterson CA, Pfister RR, Levinson RA. Aqueous humor $\mathrm{pH}$ changes after experimental alkali burns. Am J Ophthalmol. 1975;79:414-9.

80. Imanishi J, Kamiyama K, Iguchi I, Kita M, Sotozono C, Kinoshita S. Growth factors: importance in wound healing and maintenance of transparency of the cornea. Prog Retin Eye Res. 2000;19:113-29.

81. Pfister RR, Paterson CA. Ascorbic acid in the treatment of alkali burns of the eye. Ophthalmology. 1980;87:1050-7.

82. Pfister RR. Chemical injuries of the eye. Ophthalmology. 1983;90:1246-53.

83. Levinson RA, Paterson CA, Pfister RR. Ascorbic acid prevents corneal ulceration and perforation following experimental alkali burns. Invest Ophthalmol. 1976;15:986-93.

84. Petroutsos G, Pouliquen Y. Effect of ascorbic acid on ulceration in alkali-burned corneas. Ophthalmic Res. 1984;16:185-9.

85. Pfister RR, Paterson CA, Spiers JW, Hayes SA. The efficacy of ascorbate treatment after severe experimental alkali burns depends upon the route of administration. Invest Ophthalmol Vis Sci. 1980;19:1526-9. 
86. Pfister RR, Haddox JL, Yuille-Barr D. The combined effect of citrate/ascorbate treatment in alkali-injured rabbit eyes. Cornea. 1991;10:100-4.

87. Sharma N, Mohanty S, Jhanji V, Vajpayee RB. Amniotic membrane transplantation with or without autologous cultivated limbal stem cell transplantation for the management of partial limbal stem cell deficiency. Clin Ophthalmol. 2018; 12:2103-6.

88. Basu S, Sureka SP, Shanbhag SS, Kethiri AR, Singh V, Sangwan VS. Simple limbal epithelial transplantation: long-term clinical outcomes in 125 Cases of unilateral chronic ocular surface burns. Ophthalmology. 2016;123:1000-10.

89. Basu S, Mohan S, Bhalekar S, Singh V, Sangwan V. Simple limbal epithelial transplantation (SLET) in failed cultivated limbal epithelial transplantation (CLET) for unilateral chronic ocular burns. Br J Ophthalmol. 2018;102:1640-45.

90. Saghizadeh M, Kramerov AA, Svendsen CN, Ljubimov AV. Concise review: stem cells for corneal wound healing. Stem Cells. 2017;35:2105-14.

91. Cheung AY, Sarnicola E, Holland EJ. Long-term ocular surface stability in conjunctival limbal autograft donor eyes. Cornea. 2017;36:1031-5.

92. Zhao Y, Ma L. Systematic review and meta-analysis on transplantation of ex vivo cultivated limbal epithelial stem cell on amniotic membrane in limbal stem cell deficiency. Cornea. 2015;34:592-600.

93. Yin J, Jurkunas U. Limbal Stem cell transplantation and complications. Semin Ophthalmol. 2018;33:134-41.

94. Shanbhag SS, Saeed HN, Paschalis EI, Chodosh J. Keratolimbal allograft for limbal stem cell deficiency after severe corneal chemical injury: a systematic review. $\mathrm{Br} \mathrm{J}$ Ophthalmol. 2018;102:1114-21.

95. Baradaran-Rafii A, Delfazayebaher S, Aghdami N, Taghiabadi E, Bamdad S, Roshandel D. Midterm outcomes of penetrating keratoplasty after cultivated oral mucosal epithelial transplantation in chemical burn. Ocul Surf. 2017;15:789-94.

96. Lang SJ, Böhringer D, Geerling G, Reinhard T. Long-term results of allogenic penetrating limbo-keratoplasty: 20 years of experience. Eye. 2017;31:372-8.

97. Basu S, Fernandez MM, Das S, Gaddipati S, Vemuganti GK, Sangwan VS. Clinical outcomes of xeno-free allogeneic cultivated limbal epithelial transplantation for bilateral limbal stem cell deficiency. Br J Ophthalmol. 2012;96:1504-9.

98. Gupta N, Farooqui JH, Patel N, Mathur U. Early results of penetrating keratoplasty in patients with unilateral chemical injury after simple limbal epithelial transplantation. Cornea. 2018;37:1249-54

99. Sotozono C, Inatomi T, Nakamura T, Koizumi N, Yokoi N, Ueta $\mathrm{M}$, et al. Cultivated oral mucosal epithelial transplantation for persistent epithelial defect in severe ocular surface diseases with acute inflammatory activity. Acta Ophthalmol. 2014;92: e447-53.

100. Movahedan A, Cheung AY, Eslani M, Mogilishetty G, Govil A, Holland EJ. Long-term outcomes of ocular surface stem cell allograft transplantation. Am J Ophthalmol. 2017;184:97-107.

101. Pellegrini G, Lambiase A, Macaluso C, Pocobelli A, Deng S, Cavallini GM, et al. From discovery to approval of an advanced therapy medicinal product-containing stem cells, in the EU. Regen Med. 2016;11:407-20.

102. National Institute for Health and Care Excellence (NICE). Holoclar for treating limbal stem cell deficiency after eye burns. Technology appraisal guidance [TA467]. Published: 16 August 2017 https://www.nice.org.uk/guidance/ta467.

103. Shanbhag SS, Saeed HN, Paschalis EI, Chodosh J. Boston keratoprosthesis type 1 for limbal stem cell deficiency after severe chemical corneal injury: a systematic review. Ocul Surf. 2018;16:272-81.

104. Ciolino JB, Belin MW, Todani A, Al-Arfaj K, Rudnisky CJ. Boston Keratoprosthesis Type 1 Study G. Retention of the Boston keratoprosthesis type 1: multicenter study results. Ophthalmology. 2013;120:1195-200.

105. Vasquez-Perez A, Zarei-Ghanavati M, Avadhanam V, Liu C. Osteo-odonto-keratoprosthesis in severe thermal and chemical injuries. Cornea. 2018;37:993-9.

106. Tan A, Tan DT, Tan XW, Mehta JS. Osteo-odonto keratoprosthesis: systematic review of surgical outcomes and complication rates. Ocul Surf. 2012;10:15-25.

107. Kuckelkorn R, Keller GK, Redbrake C. Glaucoma after extremely severe chemical and thermal eye burns. Surgical possibilities. Ophthalmologe. 2001;98:1149-56.

108. Cade F, Grosskreutz CL, Tauber A, Dohlman CH. Glaucoma in eyes with severe chemical burn, before and after keratoprosthesis. Cornea. 2011;30:1322-7.

109. Tsai JH, Derby E, Holland EJ, Khatana AK. Incidence and prevalence of glaucoma in severe ocular surface disease. Cornea. 2006;25:530-2.

110. Kuckelkorn R, Kottek A, Reim M. Intraocular complications after severe chemical burns--incidence and surgical treatment. Klin Monbl Augenheilkd. 1994;205:86-92.

111. Chen SY, Fong PC, Lin SF, Chang CH, Chan CC. A casecrossover study on transient risk factors of work-related eye injuries. Occup Environ Med. 2009;66:517-22.

112. Lin MP, Eksioglu U, Mudumbai RC, Slabaugh MA, Chen PP. Glaucoma in patients with ocular chemical burns. Am J Ophthalmol. 2012;154:481-5 e1.

113. Shah A, Blackhall K, Ker K, Patel D. Educational interventions for the prevention of eye injuries. Cochrane Database Syst Rev. 2009: CD006527. https://doi.org/10.1002/14651858.CD006527.pub3.

114. Executive HaS. First aid at work - the health and safety (firstaid) regulations 1981. The Stationery Office; 2013. p. 9. 